\title{
Avaliação da Eficiência da Prova Qualitativa de Cloretos para Investigação de Adulteração do Leite
}

\author{
1,* Marcela Thaísa Carlindo Fornasari, Maike Taís Maziero Montanhini. \\ ${ }^{1}$ Faculdade Evangélica do Paraná, Paraná - Brazil \\ * marcelacf.vet@ hotmail.com
}

Resumo: O leite é um produto susceptível a fraudes, sendo a adição de água uma das formas mais comuns. Esta é considerada uma fraude econômica comumente utilizada para aumentar o volume de leite comercializado. Uma das substâncias utilizadas para mascarar a presença de água no leite é o cloreto de sódio, caracterizado como reconstituinte, com a finalidade de corrigir a densidade e a crioscopia do leite. O objetivo deste trabalho foi avaliar a eficiência e sensibilidade da análise qualitativa de cloretos para a detecção da presença deste adulterante no leite. Foram coletadas 96 amostras de leite de vacas em diferentes estágios de lactação e realizada a análise qualitativa de cloretos e a contagem de células somáticas. Os resultados demonstraram que a prova de cloretos não pode ser utilizada como base para detectar irregularidades, pois a prova apresentou resultado positivo mesmo no leite de animais recém-ordenhados, ou seja, que não foi submetido a fraudes.

Palavras-chaves: fraude; reconstituinte de densidade; cloreto.

Evaluation of the efficiency of qualitative test of chloride for investigation milk adulteration: The milk is a sensitive product for fraud, being the water addition the commom forms and is considered a economic fraud, once your composition changes. The commom substances used for fudge the water presence is the sodium chloride, characterized with restorative, in order to correct the milk density and cryoscopy. The objective of this work is evaluate the quality and sensibility of qualitative analysis of chlorides for detection water or salt. Were collected 96 milk samples of cows in different stages of lactation and the milk underwent the qualitative choride research and Somatic Cells Count analysis. The results demonstrate that chlorides evidence can't be used for detection frauds, because observed the presence of chlorides in fresh milk for animals, in other words, which wasn't subject for frauds.

Keywords: fraud; density restorative; chloride.

Recebido: 26 de Fevereiro de 2015; aceito: 26 de Maio de 2015, publicado: 11 de Dezembro de 2015. DOI: $10.14685 /$ rebrapa.v6i2.209

\section{INTRODUÇÃO}

O leite possui em média $3,5 \%$ de proteínas, $3,8 \%$ de gordura, $5,0 \%$ de lactose, $0,7 \%$ de minerais (cinzas) e $87 \%$ de água, sendo este seu constituinte quantitativamente mais importante (BEHMER, 1999). Apresenta todas as vitaminas conhecidas e teores consideráveis de cloro, fósforo, potássio, sódio, cálcio, magnésio e baixos teores de ferro, alumínio, bromo, zinco e manganês, formando sais minerais orgânicos e inorgânicos (SILVA et al., 1997).
A adulteração do leite por adição de água é uma fraude econômica comumente utilizada para aumentar o volume de leite comercializado. No entanto, esta fraude pode ser facilmente detectada pelo controle de qualidade realizado pelos laticínios. Como forma de mascarar a adição de água do leite, são utilizados agentes reconstituíntes de densidade, entre eles, o sal de cozinha (cloreto de sódio) (TRONCO, 2008).

A determinação qualitativa de cloretos no leite baseia-se na ação do nitrato de prata em 
presença do indicador cromato de potássio. Quando o teor de cloretos é normal, a quantidade de nitrato de prata adicionada é excessiva, reagindo, então, com o indicador para a obtenção da cor marrom. Se o teor de cloreto é elevado, haverá maior consumo de nitrato de prata, diminuindo a intensidade da coloração marrom (TRONCO, 2008). Esta análise é recomendada pela legislação brasileira para a pesquisa de reconstituíntes de densidade (BRASIL, 2006).

No entanto, o leite com elevada contagem de células somáticas (CCS) também apresenta teores de cloretos acima do normal, o que pode causar um resultado falso-positivo, levando a supor que o leite foi fraudado com a adição de cloreto de sódio. Os íons cloreto e os íons sódio estão presentes na circulação sanguínea e durante a mastite atravessam os capilares sanguíneos, direcionando-se ao lúmen dos alvéolos da glândula mamária. Tal processo ocorre devido ao aumento da permeabilidade vascular e à destruição das junções celulares e do sistema de bombeamento iônico causados pelo processo inflamatório (ZAFALON et al., 2005).

Em função destes aspectos, objetivou-se o presente trabalho, de modo a identificar se a prova qualitativa de cloretos é eficiente para a avaliação da adulteração do leite por adição deste sal.

\section{MATERIAL E MÉTODOS}

Foram avaliadas 96 amostras de leite de 48 vacas da raça holandesa em diferentes períodos de lactação, em uma granja leiteira de sistema free stall, localizada na região de Palmeira/PR em março de 2013.

As amostras foram coletadas diretamente no balão individual após o término da ordenha da tarde e da manhã do dia seguinte, sendo utilizados 3 frascos para cada animal, dois frascos eram destinados para análise de cloretos e o outro para análise de CCS.
Durante e após a coleta todas as amostras foram mantidas sob refrigeração e em seguida encaminhadas para o laboratório.

Para a análise da CCS, foi utilizado o frasco contendo bronopol fornecido pelo laboratório da Associação Paranaense de Criadores de Bovinos da Raça Holandesa (APCBRH). Na ordenha da tarde foi adicionado metade da amostra no frasco e na manhã seguinte foi utilizado o mesmo frasco, sendo este totalmente preenchido com mais metade da amostra. No mesmo dia as amostras foram enviadas ao laboratório da APCBRH.

Para a análise qualitativa de cloretos, foram coletadas duas amostras, sendo uma para cada turno em frascos devidamente identificados. A prova de cloretos foi realizada de acordo com a Instrução Normativa $\mathrm{n}^{\mathrm{o}} 68$ (IN68), sendo utilizado $10 \mathrm{~mL}$ de leite em tubo de ensaio, em seguida, adicionados $0,5 \mathrm{~mL}$ de solução de cromato de potássio a $5 \%$ e $4,5 \mathrm{~mL}$ de solução de nitrato de prata. $\mathrm{O}$ surgimento de coloração amarela indica resultado positivo e a coloração marrom resultado negativo (BRASIL, 2006).

\section{RESULTADOS E DISCUSSÕES}

Os resultados obtidos na análise qualitativa de cloretos e Contagem de Células Somáticas (CCS) estão apresentados na Tabela 1.

A análise qualitativa de cloretos apresentou resultados positivos em leite de animais recémordenhados. Este é um dado preocupante, considerando que a prova de cloretos é utilizada para identificar adulteração por adição de sal de cozinha, um reconstituínte de densidade utilizado para mascarar a adição de água no leite.

Vários autores afirmam que a Contagem de Células Somáticas pode exercer influência no teor de cloretos no leite (ZAFALON et al., 2005; SANTOS et al., 2003; ELIAS et al., 2005). As alterações na composição do leite associadas com a contagem de células somáticas (CCS) indicam que contagens abaixo de 100.000 $\mathrm{CCS} / \mathrm{mL}$ já apresentam $0,091 \mathrm{~g}$ de cloro por 100 
mL de leite (SANTOS et al., 2003). A medida que se eleva a CCS na mastite subclínica, há um aumento do teor de cloretos (ELIAS et al., 2005). O limite de detecção da prova de cloretos é de 0,08 a $0,1 \%$, ou seja, amostras com CCS dentro dos limites previstos pela IN62 já apresentariam resultados positivos neste teste (BRASIL, 2006).

Tabela 1 - Resultados de determinação de cloretos na ordenha da manhã e da tarde e contagem de células somáticas em 48 vacas em lactação avaliadas em março de 2013 em uma propriedade da região de Palmeira/ PR.

\begin{tabular}{|c|c|c|c|}
\hline \multicolumn{2}{|c|}{ Cloretos } & \multirow{2}{*}{$\begin{array}{c}\text { Resultados } \\
\text { CCS }\end{array}$} & \multirow{2}{*}{$\begin{array}{c}\mathbf{N}^{\circ} \text { de } \\
\text { Amostras }\end{array}$} \\
\hline (Manhã) & (Tarde) & & \\
\hline+ & + & Alta CCS* & 4 \\
\hline+ & - & Alta CCS & 5 \\
\hline- & + & Alta CCS & 2 \\
\hline- & - & Alta CCS & 8 \\
\hline+ & + & $\begin{array}{c}\text { Baixa } \\
\text { CCS** }\end{array}$ & 1 \\
\hline+ & - & Baixa CCS & 2 \\
\hline- & + & Baixa CCS & 1 \\
\hline- & - & Baixa CCS & 25 \\
\hline
\end{tabular}

*Alta CCS > 600.000

**Baixa CCS $<600.00$

Como observado na Tabela 1, apenas uma amostra apresentou a presença de cloretos no turno da manhã e da tarde, sendo que o resultado de CCS apresentaram-se em 205.000 CCS/mL e, ou seja, este resultado apresenta-se dentro do limite estipulado pela IN62. Já 8 amostras indicaram a ausência de cloretos tanto na ordenha da manhã quanto na ordenha da tarde, apresentando valores de CCS bem acima do permitido pela IN62.

Quatro amostras apresentaram resultados positivos nas provas de cloretos realizadas no período da manhã e da tarde e elevadas contagens de CCS. As demais amostras apresentaram-se com variados resultados nas provas de cloretos tanto na ordenha da manhã quanto na ordenha da tarde.

Embora muitos autores tentem explicar ou até mesmo comprovar a relação entre cloretos e CCS, observa-se através deste trabalho uma baixa relação entre estes indicadores, pois apenas 11 amostras apresentaram alguma positividade na presença de cloretos relacionada a alta CCS. A prova de cloretos também é utilizada por alguns pesquisadores para detectar mastite subclínica, em função do aumento da CCS no leite (TRONCO, 2008). Como observado nos resultados obtidos, além de comprovarem que não existe relação constante entre alta CCS e teores de cloretos no leite, mostram que o teste de cloretos não é adequado para o diagnóstico da mastite subclínica.

Não há uma relação entre o teor de cloretos e a incidência de mastite subclínica, bem como o teor de cloretos e o CMT, ou seja, o teste de teor de cloretos não apresenta sensibilidade em relação à detecção de mastite subclínica (ASSIS, et al., 2008). São necessários maiores estudos quanto à relação existente entre a mastite subclínica e o aumento no teor de cloretos. Alguns autores avaliaram os indicadores inflamatórios utilizados para o diagnóstico da mastite bovina, desta forma, concluíram que a CCS e o CMT apresentaram-se como ferramentas confiáveis para o diagnóstico da mastite, não podendo o mesmo ser aplicado para os demais testes (DELLA LIBERA et al., 2011).

A prova de cloretos no diagnóstico da mastite subclínica deve ser utilizada de forma cautelosa, uma vez que a ocorrência de resultados falsopositivos pode acarretar elevados prejuízos econômicos. Além disso, os autores assinalaram a importância dessas informações no sentido de oferecer subsídios que propiciem o aumento da eficiência desse método auxiliar de diagnóstico 
(AMARAL et al., 1998; VASCONCELOS et al., 1997).

Os dados deste trabalho também apontam diferenças nos resultados de cloretos em função do turno da ordenha. Observa-se maior presença de cloretos no turno da manhã, sendo que 12 amostras se apresentaram positivas para o teste. Já na ordenha do turno da tarde 8 amostras apresentaram positividade para cloreto.

Estas alterações, com relação a variação da presença de cloretos em turnos diferentes, podem ser explicadas por outros fatores que podem influenciar diretamente nas alterações de cloretos no leite, tais como diferenças individuais, número de lactações, variações diurnas, estágio de lactação e sazonalidade. A não consideração desses fatores poderá implicar em testes falso-positivos, resultando em graves consequências econômicas, representadas principalmente por tratamentos desnecessários e pelo descarte do leite (BARROS; LEITÃO, 1992). Outros autores focam a importância de ressaltar que vários fatores podem acarretar alterações relacionadas a presença de cloretos no leite (AMARAL et al., 1998; VASCONCELOS et al., 1997).

Este trabalho baseou-se na metodologia descrita na IN 68 para a análises de teor de cloretos no leite (BRASIL, 2006). A partir dos resultados encontrados podemos inferir que este teste não é apropriado para a detecção de fraudes, pois além de apresentar resultados falso-positivos, a prova é de difícil interpretação, uma vez apresenta uma grande variedade de tonalidades nos resultados, o que é inapropriado para uma prova qualitativa.

De acordo com Silva, a prova de cloretos é extremamente sensível e apresenta baixo nível de detecção $(0,027 \%)$ de $\mathrm{NaCl}$. Justamente por apresentar tamanha sensibilidade a prova se torna inadequada, pois o teor de cloretos no leite pode sofrer influência de fontes naturais e fisiológicas do animal, não sendo necessariamente de fontes exógenas (SILVA et al., 2011).

A prova de cloretos é utilizada por muitos laboratórios e laticínios para detectar fraudes, uma vez que o cloreto de sódio é utilizado como reconstituinte de densidade e seu uso é destinado para mascarar a adição de água no leite, promovendo alterações em sua composição. Os resultados deste estudo demonstram que esta prova pode ser influenciada por diversos fatores, portanto, não é adequada para diagnóstico de fraude.

\section{CONCLUSÃO}

Os resultados demonstraram que a prova de cloretos não é adequada como base para detectar fraudes por adição de cloreto de sódio, devido a difícil interpretação do teste e pelo fato de que a presença de cloretos no leite nem sempre pode ser interpretado como uma fraude econômica, pois foi observado a presença do mesmo no leite de animais recém-ordenhados, ou seja, que não foi submetido a fraudes.

\section{AGRADECIMENTOS}

Os autores agradecem ao laticínio Lactobom por ter permitido a prática destas análises em seu laboratório e ao Coordenador da empresa Júlio Barszcz pelo apoio, dedicação e confiança para a realização deste trabalho.

\section{REFERÊNCIAS BIBLIOGRÁFICAS}

Amaral, L. A.; Nader Filho, A.; Lew, B. J. Estudo da variação do teor de cloretos no colostro e no leite de vacas sadias. Ars Veterinary. v.4, p.105-112, 1998.

Assis, D.Y.C.; Souza, D.R.M.; Marques, B.A.A.; Almeida, F.C.; Carvalho, M.G.X.; Souza, B.B. California mastit test e pesquisa de cloretos como métodos indiretos de diagnóstico da mastite subclínica, Anais: $47^{\circ}$ Reunião Anual da Sociedade Brasileira de Zootecnia mai./jul., 2008.

Barros, G.C.; Leitão, C.H. Influência da mastite sobre as características físico-químicas do leite 
de cabra. Pesquisa Veterinária Brasileira. v.12, p.45-48, 1992.

Behmer, M. L. A. Tecnologia do leite: queijo, manteiga, caseína, iogurte, sorvetes e instalações: produção, industrialização, análise. 13. ed. São Paulo: Nobel, 1999.

Brasil. Ministério da Agricultura, Pecuária e Abastecimento. Instrução Normativa ${ }^{\circ} 68$ de 12 de dezembro de 2006. Oficializa os Métodos Analíticos Oficiais Físico-Químicos, para Controle de Leite e Produtos Lácteos. Diário Oficial [da] República Federativa do Brasil, Brasília, 14 dezembro 2006, p.8, Seção 1, 12 de dezembro de 2006.

Della Libera, A.M.M.P.; Souza, F.N.; Blagitz, M.G.; Batista, C.F. Avaliação dos indicadores inflamatórios no diagnóstico da mastite bovina. Arquivos do Instituto de Biologia, São Paulo, v.78, n.2, p.297-300, 2011.

Elias. A. O. et al. Características físico-químicas e contagem de células somáticas de leite proveniente de vacas naturalmente infectadas por Streptococcus spp. Arquivos de Ciência Veterinaria e Zoologia. Unipar, v.8, n.2, p.165-170, 2005.

Santos, M. V.; Influência da qualidade do leite na manufatura e vida de prateleira dos produtos lácteos: papel das células somáticas. In: Brito, J. R. F.; Portugal J. A . B. (Org). Diagnóstico a qualidade do leite, impacto para a indústria e a questão dos resíduos de antibióticos. Juiz de Fora, 2003, (I), p. 139-149.

Silva, P.H.F.; Pereira, D.B.C.; Oliveira, L.L. \& Costa Junior, L.C.G. Físico-química do leite. Métodos analíticos. Juiz de Fora: Gráfica Oficina de Impressão, 1997.

Silvia, L.C.C.; Rios, E.A.; Junior, J.C.R.; Tamanini, R.; Ramos, J.; Silva, F.A.; Beloti, V. Sensibilidade da prova para a pesquisa de cloretos em leite pasteurizado. Anais: $38^{\circ}$ Conbravet: Congresso Brasileiro de Medicina Veterinária. Nov., 2011.
Tronco, Maria. Manual para Inspeção da Qualidade do Leite. $3^{\text {a }}$ ed. Santa Maria: UFSM, 2008.

Vasconcelos, C.G.C.; Nader Filho, A.; Amaral, L.A., et al. Influência da estação do ano, do estádio da lactação e da hora da ordenha sobre o número de células somáticas do leite bovino. Arquivos Brasileiros de Medicina Veterinária e Zootecnia. v.49, p.483-491, 1997.

Zafalon L. F.; Nader Filho A.; Oliveira J. V.; Resende F. D. Comportamento da condutividade elétrica e do conteúdo de cloretos como métodos auxiliares de diagnóstico da mastite subclínica bovina. Pesquisa Veterinária Brasileira., Rio de Janeiro, v.25, n.3, p.150- 163, 2005. 